\title{
An Analytical Study on Adoption of Resistive Economy as a Political Strategy in Urban Management and Municipalities (Case Study: Zahedan Municipality)
}

\author{
Seyed Moslem Seyedhosseini ${ }^{1}$ \\ ${ }^{1}$ Assistant professor, Department of Urban Design and Planning, Mashhad Branch, Islamic Azad University, \\ Mashhad, Iran \\ Correspondence: Seyed Moslem Seyedhosseini, Assistant professor, Department of Urban Design and Planning, \\ Mashhad Branch, Islamic Azad University, Mashhad, Iran.
}

Received: December 1, 2015

Accepted: December 29, 2015

Online Published: February 2, 2015

doi:10.5539/mas.v10n4p88

URL: http://dx.doi.org/10.5539/mas.v10n4p88

\begin{abstract}
Nowadays, municipalities provide services to more than 70 percent of countries around the world, particularly the developing countries. Nevertheless, the important role of such nongovernmental institutions has not been adequately recognized in realization of resistive economic policies. As a large Iranian city, Zahedan has the capability to become an economic hub in the eastern region of the country due to its unique geographical location. Thus, the municipality of Zahedan can play an invaluable role in achieving such a goal. This paper attempts to discuss the most important challenges facing municipalities, including the municipality of Zahedan in line with fulfillment of the resistive economic policy. These challenges are categorized into four areas including: Laws and regulations, administrational issues, human resources and citizen participation. The methodology is descriptive-analytical. Moreover, the data were analyzed in terms of statistical measures through SPSS. The results indicates that the greatest challenge concerning the faded role of municipalities in the urban economy originates respectively from laws and regulations, administrational issues, human resources and citizen participation.
\end{abstract}

Keywords: resistive economy, urban management, sustainable urban development, citizen participation

\section{Introduction}

In today's circumstances where the resistive economy is discussed, the Iranian government is encountering numerous difficulties in achieving its goals. In this respect, it seems crucial to take a great step in the economic sphere so as to reform the role of municipalities. Resistive economy refers to identification of pressure points subsequently striving to ideally control and turn such pressures into opportunities. This will be realized definitely through public participation, collective belief and adoption of rational management as a vital requirement.

In recent decades, urban management in Iran has been increasingly facing numerous challenges, which is due to various social, cultural, political, administrative, financial and legal factors. In other words, urban growth and development are an outcome of how other variables of economy and general culture have developed. Urban development can be regarded the result of unplanned development or product of decisions taken by the authorities at various levels based on the current situation and their expectations of what will happen next. The rapid and often violent growth in cities constitutes one of the issues building on the urban problems (Development and Planning of the Iranian Interior Ministry, 2002). Moreover, urban management in the metropolitan areas will no longer able to solve these problems through traditional methods (Rezai, 1996). The general approach in a dynamic urban management involves to what extent the public opinion and the collective capability can be employed to administer the city, so as to achieve a financial promotion as well as spiritual improvement, i.e. involvement of people in the urban administration. The urban financial promotion will remain stable as long as spiritual improvement persists. Therefore, one of the key issues in the economic growth of cities is how urban management succeeds in attracting greater participation of citizens. In fact, municipality has been created as a local, nongovernmental organization so as to administer the local affairs and provide services aimed at managing and developing the physical, economic and social aspects within and surrounding the city. In fact, it is supposed to fulfill the common needs of citizens, which cannot be realized by each individual alone 
(University of Sistan and Baluchestan, 2013).

With an understanding of current challenges at the Iranian municipalities concerning the resistive economy issues, this study intended to explain the challenges in various interrelated areas, their interactions and priorities, so as to propose several strategies to resolving or curtailing such challenges.

\subsection{Statement of the Problem and Significance of the Study}

Zahedan, the central city of Sistan and Baluchestan province, has been hosting the population for 90 years. It initially developed with political and administrative functions. Later on, the city absorbed in other urban service sectors such as business and commerce, education, military, craftsmanship, immigration etc., ultimately turning into one of the greatest Iranian cities. Although Zahedan does not come from an ancient history, it has set the desirable ground for demographic, physical and economic expansion due to its political and geographical position. Therefore, Zahedan has the potential to become an economic hub in the eastern region of Iran, owing to its extended land and sea borders, adjacency to the neighboring countries (Afghanistan \& Pakistan), and connection to the international railways as a remarkable economic hub in the country paving the road for realization of the Iranian economic policies.

One of the major reasons behind the significant growth in Zahedan lies in economic relations with neighboring countries, especially Afghanistan and Pakistan. Hence, there is the capacity in both neighboring countries, thank to their great population of the two countries as well as their current economic, social and cultural situations, become a safe destination for Iranian goods, leaving positive impact on the country's economy as well as development of the less-privileged Zahedan. Furthermore, the Iran-Afghanistan-Pakistan joint borders can, given the tendency of either side, resolve many of the barriers to importation of basic commodities, especially rice and beans. Reliance on the potential capability of this border and the desire of many residents from both countries for consuming the Iranian goods can set the ground for economic growth in the eastern part and realization of the resistive economic policies.

\subsection{Objectives of the Study}

- Evaluating the role of municipalities in realization of resistive economic policies

- Providing optimal solutions to tackle the current problems and challenges hindering municipalities from achievement of resistive economy

- Making useful recommendations for future planning and adoption of appropriate strategies

\subsection{Hypotheses of the Study}

H1: There is a relationship between the economic growth of cities and realization of the country's resistive economy.

H2: The impact of each dimension including the laws and regulations, administrational issues, human resources and public participation varied in aggravation of municipal challenges against achievement of resistive economy.

H3: Laws and regulations are most challenging in the role of municipalities for achieving resistive economy as compared to other dimensions.

\section{Review of Literature}

\subsection{The Role of Municipalities in Realization of Resistive Economic Policies}

As a local government, every municipality plays an important role in the daily life of urban society. Meanwhile, the quality of services is becoming increasingly diversified to the extent that there is practically no action taken without the involvement of municipalities. It is essential to reflect a little on why some municipalities, in spite of their important role in cities, fail to pay adequate attention to realization of the resistive economy. Undoubtedly, it is the times of crisis and economic pressures due to high population concentration leading to extravagant household expenses. Nevertheless, municipalities can arrange a variety of local markets and identify other economic bottlenecks in the city. They can resolve the government issues concerning the supply and demand, so as to lift the initial crisis and its consequences. Moreover, they can provide the people with assistive services and accomplish the mission and objectives of the resistive economy.

\subsection{Challenges Related to Laws and Regulations}

- All municipalities agree on the fact that the current regulations have lost their effectiveness according to the needs of citizens today. Hence, it seems crucial to put the issue on agenda at government and Assembly circles. 
- Unfortunately, urban laws in many cases such as Article 5 Commission hinder the municipalities, which have surprisingly adopted initiatives in order to actualize certain decisions for resolving citizen problems.

- Laws and regulations introduce various devices into the cycle of urban economy, where the time required for coordination on how to set out and terminate economic projects sometimes leaves irreparable damages.

- The private sector and investors have lost their initial incentive in the face of cumbersome regulations in an attempt to gain approval of public organizations and agencies.

- Unfortunately, the municipalities are distinguished only based on certain factors such as population, i.e. there is insufficient consideration and privileges for borderline municipalities which can take great steps in line with the resistive economic policies.

\subsection{Administrative Challenges}

- The engaging of senior managers with the everyday problems at each municipality can distract their focus on how to achieve and implement the major policies pursued by the resistive economy.

- Poor knowledge in some officials of Zahedan and inadequate funds allocated to development of infrastructure necessary to achieve sustainable urban economy, despite great capacities in the city,

- Poor coordination of public companies in completing fundamental projects that can pave the road for realization of the urban economy and cost reduction (distribution of gas, railway, highway, etc.) Given the current and future population of Zahedan and its adjacency to Mashhad and Gorgan,

- Poor coordination of certain government agencies and nongovernmental organizations involved in urban management for achieving the economic resistive policies

- Although Zahedan enjoys a desirable standpoint as the central city in Sistan and Baluchestan as well as access to open seas, cheap abundant labor, connection to international rail etc., insufficient efforts made by some officials and early substitution of managers have so far been hindering the national economic growth in this region.

- Unfortunately, the model of concentration and dispersion of small and large industries and factories in the country has many drawbacks. For example, most heavy industries such as automobile, steel etc. have concentrated in areas leading to environmental pollution. Moreover, the capability of those lands, mostly agricultural or tourist attraction, has been deteriorated, which is incompatible with the resistive economic policies.

\subsection{Challenges Related to Human Resources}

- Lack of expert force particularly in the areas of urban economy

- lack of specialized areas in organizational charts of certain departments, agencies and companies for carrying out economic studies and investment

- Improper and unsystematic training of human resources at certain departments of municipalities for devising economic prosperity plans and utilization of available potentials

- Lack of specialized fields of study relevant to urban economy and urban economic boom at Zahedan universities despite the popularity of Zahedan as a student-absorbing city.

- Inadequate projects and studies tailored to the needs of urban economy and resistive economy

- Lack of congruity between funding and actual needs for economic prosperity of cities

\subsection{Challenges Related to Citizen Participation}

- Lack of proper definition given to participation and its levels

- Lack of public confidence in the notion of participation

- Insensitivity of authorities to the need for raising public awareness about the benefits of implementing economic projects

- Insufficient analysis of prevalent culture in line with adoption of a favorable participation approach

\section{Methodology}

This was an applied study in terms of objective. Moreover, it could be regarded as descriptive-analytical in terms of methodology, where the data were collected through desk review and field operation. In any statistical 
analysis the hypotheses and operational variables are employed to specify several indicators. Then, the relevant indicators are explained and evaluated through questionnaire and statistical measures.

The sample size was calculated through Cochran's formula (Hafeznia, 2009) and samples were selected at confidence level of $95 \%$. According to the population, a total of 129 municipal managers and experts at Zahedan municipality were selected as sample. The variables were measured through a 5-point Likert scale, the values of which were displayed in Table 1.

Table 1. Ordinal Likert scale

\begin{tabular}{ccccc}
\hline Very low & Low & Average & High & Very high \\
\hline 1 & 2 & 3 & 4 & 5 \\
\hline
\end{tabular}

In this study, the reliability of questionnaire was calculated through Cronbach's alpha in SPSS. Cronbach's alpha test was conducted through a total of 54 items. The Cronbach's alpha of the questionnaire was calculated to be 0.932 , which indicates high level of reliability.

Data were analyzed through inferential statistic measures such as single-group T-test, independent sample test, ANOVA, Pearson's correlation and Friedman's test using SPSS.

\subsection{Research Variables}

The independent and dependent variables as well as the indicators have been illustrated in Tables 2 and 3 , respectively.

Table 2. Independent and dependent variables

\begin{tabular}{ll}
\hline Independent variable & Dependent variable \\
\hline Laws and regulations, administrational issues, human & $\begin{array}{l}\text { The role of municipalities in realization } \\
\text { of resistive economy }\end{array}$ \\
resources and citizen participation &
\end{tabular}

Table 3. Indicators and Representatives

\begin{tabular}{|c|c|c|}
\hline Area & Challenging area & Representatives \\
\hline 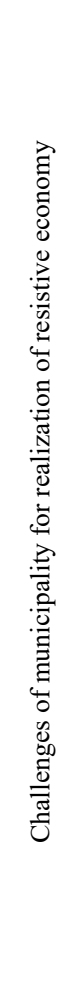 & $\begin{array}{l}\text { Administrational } \\
\text { issues }\end{array}$ & $\begin{array}{l}\text { Ineffective laws in modern days, the direct relationship between the existing laws and regulations } \\
\text { and achievement of resistive economy, cumbersome regulations, economic prosperity of cities } \\
\text { through revising laws and regulations } \\
\text { Qualitative and quantitative consistency of organizations and agencies involved in urban } \\
\text { management for achievement of urban economy, extended role of municipalities in resistive } \\
\text { economy along with population growth, adaptability of Iranian demographic distribution with the } \\
\text { requirements and standards of the urban economy, the problems arising from population growth } \\
\text { and lack of knowledge in economic and urban issues, lack of coordination among government } \\
\text { agencies involved in the urban economy, successful performance of government agencies in } \\
\text { preventing an increase in municipal costs, economic growth and prosperity of cities along with } \\
\text { elevating the status of municipalities, provision of manpower and equipment for city and } \\
\text { municipalities aligned with fulfillment of resistive economic policies. } \\
\text { Lack of expert force particularly in urban economy, lack of specialized areas in organizational } \\
\text { charts of certain departments, agencies and companies for carrying out economic studies and } \\
\text { investment, improper and unsystematic training of human resources at certain departments of } \\
\text { municipalities for devising economic prosperity plans and utilization of available potentials, lack of } \\
\text { specialized fields of study relevant to urban economy and urban economic boom at Zahedan } \\
\text { universities despite the popularity of Zahedan as a student-absorbing city, inadequate projects and } \\
\text { studies tailored to the needs of urban economy and resistive economy, lack of congruity between } \\
\text { funding and actual needs for economic prosperity of cities } \\
\text { Lack of proper definition given to participation and its levels, lack of public confidence in the } \\
\text { notion of participation, insensitivity of authorities to the need for raising public awareness about } \\
\text { the benefits of implementing economic projects, insufficient analysis of prevalent culture in line } \\
\text { with adoption of a favorable participation approach }\end{array}$ \\
\hline
\end{tabular}




\section{Data Analysis and Results}

The inferential statistics were used to test the hypotheses. The tests involved in this study were single-group T-test, independent sample test, ANOVA, Pearson's correlation and Friedman's test.

According to the results of independent T-test, the significance level was lower than 0.05 and the mean of challenges in the population for each environmental dimension was larger than average value (i.e. 3 ). On the other hand, the differences between the mean values and the upper and lower bounds in all the areas were positive. Therefore, the environmental challenges of Zahedan in different areas were far higher than the average (Table 4).

Table 4. Challenges of Zahedan municipality for realization of resistive economic policies

\begin{tabular}{ccccccccc}
\hline & \multicolumn{9}{c}{ Test value=3 } \\
\cline { 2 - 8 } $\begin{array}{c}\text { Different areas of } \\
\text { urban environment }\end{array}$ & $\begin{array}{c}\text { Population } \\
\text { average }\end{array}$ & T-value & $\begin{array}{c}\text { Degree of } \\
\text { freedom }\end{array}$ & $\begin{array}{c}\text { Significance } \\
\text { level }\end{array}$ & $\begin{array}{c}\text { Mean } \\
\text { difference }\end{array}$ & $\begin{array}{c}\text { Confidence level } \\
\text { of 95\% }\end{array}$ \\
\hline $\begin{array}{c}\text { Human resources } \\
\text { Administrational }\end{array}$ & 3.80 & 20.8 & 128 & 0.000 & 0.806 & 0.729 & $\begin{array}{c}\text { Lower } \\
\text { bound }\end{array}$ & $\begin{array}{c}\text { Upper } \\
\text { bound }\end{array}$ \\
$\begin{array}{c}\text { issues } \\
\text { Citizen participation }\end{array}$ & 4 & 18.73 & 128 & 0.000 & 1.003 & 0.897 & 1.109 \\
Laws and regulations & 4.87 & 14.14 & 128 & 0.000 & 0.868 & 0.746 & 0.989 \\
Total & 4.04 & 18.26 & 128 & 0.000 & 1.042 & 0.929 & 1.156 \\
\hline & 3.81 & 20.74 & 128 & 0.000 & 0.807 & 0.730 & 0.884 \\
\hline
\end{tabular}

\subsection{First Hypothesis Testing}

H1: There is a significant relationship between the economic growth of cities and realization of the country's resistive economy.

The results of the independent t-tests showed that the significance level was lower than 0.05 and the mean of challenges in the population (role of Zahedan municipality) for each environmental dimension was larger than average value (i.e. 3). On the other hand, the differences between the mean values and the upper and lower bounds in all the areas were positive. Therefore, the role of Zahedan municipality in realization of resistive economic policies was far higher than the average. Hence, the first hypothesis is proved. It can be argued there is a relationship between the economic growth of cities and realization of the country's resistive economy.

\subsection{Second Hypothesis Testing}

H2: The impact of each dimension including the laws and regulations, administrational issues, human resources and public participation varied in aggravation of municipal challenges against achievement of resistive economy.

The results of Friedman's test at confidence level of $95 \%$ indicated that the significance level was lower than 0.05 , i.e. there is a significant difference between the municipal areas of challenges against achieving the resistive economic policies in Zahedan. The laws and regulation and administrational issues were far more challenged, ranking the first and second places, respectively. Moreover, the human resources and citizen participation made the smallest contribution in realization of resistive economy. It implies that the impact of each dimension including the laws and regulations, administrational issues, human resources and public participation varied in aggravation of municipal challenges against achievement of resistive economy.

According to Pearson's correlation, there is a strong relationship between the role of municipalities and realization of resistive economic policies from different perspectives in the cities.

\subsection{Third Hypothesis Testing}

H3: Laws and regulations are most challenging in the role of municipalities for achieving resistive economy as compared to other dimensions.

The results of Friedman test and Pearson correlation indicated that laws and regulations played the largest role in realization of resistive economic policies on the part of municipalities, whereas other dimensions such as administrational issues, human resources and citizen participation took up the next rankings. Therefore, the third hypothesis is confirmed. 


\section{Conclusion}

This study was based on experts' and managers' viewpoints at some Iranian municipalities and affiliated organizations and leaders, examining the role of municipalities in realization of resistive economic policies in Zahedan. In fact, this study intended to gain a better understanding of the current challenges and how they expand the role of municipalities in order to achieve resistive economy. Finally, the challenges were prioritized in order to help planners and policy-makers in Zahedan take more systematic and targeted measures. There were several results obtained in this study.

The majority of the selected subjects $(82.2 \%)$ believed that municipalities can play an important role in achieving the country's resistive economic policies. Moreover, inadequate attention paid to the current problems of cities and municipalities can lead to failure in achievement of objectives pursued by the Iranian resistive economy. According to the inferential statistics about municipalities and their role in realization of resistive economy, there are numerous difficulties in various dimensions greater than average.

By examining the role of municipalities in fulfilling the resistive economic policies, it was revealed that laws and regulations made the largest contribution to challenges as compared to other dimensions. This implies that certain laws and regulations need to be modified in order to facilitate the role of municipalities in line with resistive economic policies in most cities. Administrational issues, human resources and citizen participation took up the second, third and fourth places, respectively.

Further, the results indicated that there is a significant relationship between environmental challenges in various areas and population growth. It can be argued that all the environmental resources are extremely affected by the ever-increasing population growth in Zahedan although the degree of influence may be different in different areas.

\section{Recommendations of the Study}

Given the methodology and the results, there are several recommendations presented below. First of all, the recommendations are discussed generally for the area of planning and urban development, and will then be separated into various areas in order to fix the problems in the future.

\subsection{General Recommendations}

- Adoption of research-based management approach in different sectors of urban resistive economy and metropolitan areas based on the views of municipal experts, specialists outside the municipality relying on research findings and studies to be carried out so as to avoid personal judgment in actual planning of resistive economy.

- Conducting studies so as to provide scientific and practical solutions to the problems facing the urban economy and achievement of dynamic and sustainable urban development in metropolitan cities

- Implementation of development projects based on prioritization as well as sustainable development of cities and urban economy

- Development and utilization of information and communication technologies so as to achieve the resistive economic policies

- Dividing the city into smaller areas and extending oversight in line with realization of objectives pursued by the Iranian resistive economic policies

- Revising the detailed plan aimed at growth and prosperity of urban economy in large cities and addressing the comments and opinions expressed by all the agencies involved in urban management

- Allocation of funds according the requirements of each urban economy project

- Employment of the expertise of consultants for outlining the objectives and strategies to achieve the urban economy and resistive economic policies

\subsection{Recommendations for Each Area}

\section{Laws and regulations}

- Revising the laws and regulations and eliminating troublesome regulations so as to achieve more of the goals and policies of resistive economy pursued in cities and metropolitan areas.

- Building transparency in laws and regulations so as to resolve ambiguities

Administrational issues 
- Employment of managers competent in financial and economic regulations concerning areas directly linked with resistive economy

- Outlining clearly achievable objectives appropriate to the circumstances of each city

- Explaining specific guidelines and procedures to achieve goals

- Assigning specific measureable tasks

- Receiving feedback on the actions taken

- Reforming the objectives pursued by each task if necessary

- Obtaining expert opinion for replacement of capabilities of various cities and surrounding lands, particularly the municipalities.

\section{Human resources}

- Training the municipal staff, other agencies and institutions involved in urban management

- Recruiting specialists in appropriate organizational positions

Citizen Participation

- Creating an effective, gradual partnership, so as to solicit participation of citizens based a broad range of techniques appropriate to the circumstances and preferences of each participant. The following methods can be helpful to attract maximum participation:

- Surveying citizens in economic plans and programs and offering incentives to encourage ideas and solutions

- Raising awareness and planning to observe the effect of citizen participation in successful development of programs by increasing the sense of belonging in individuals

- Identifying popular highly supported figures among the citizens and holding seminars so as to encourage people to participate

- Citizenship training and culturalization

\section{References}

Consulting Engineers for City and Home. (2010). Last revision of the detailed plan of Zahedan. Sistan and Baluchestan Province Department of Housing and Urban Development.

Hafeznia, M. R. (2009). An introduction to research in the humanities. Tehran, SAMT, 2009.

Rezai, A. (1996). Social participation, goal or means of development. Political and economic information magazine, 109-110, Institute of Information.

Saifuddini, F. (1997). Public participation and development planning. Journal of Social Sciences and Humanities, University of Shiraz, 2.

University of Sistan and Baluchestan. (2013). A comprehensive project for optimum solutions to efficient utilization of urban economic potentials with an emphasis on resource management and financial expenses in Zahedan.

\section{Copyrights}

Copyright for this article is retained by the author(s), with first publication rights granted to the journal.

This is an open-access article distributed under the terms and conditions of the Creative Commons Attribution license (http://creativecommons.org/licenses/by/3.0/). 